\title{
Lawrence Livermore National Laboratory Safeguards and Security Quarterly Progress Report to the U.S. Department of Energy
}

\section{Quarter Ending September 30, 1993}

\author{
Wayne D. Ruhter \\ R. Scott Strait \\ Doug L. Mansur \\ Greg Davis
}

October 1993

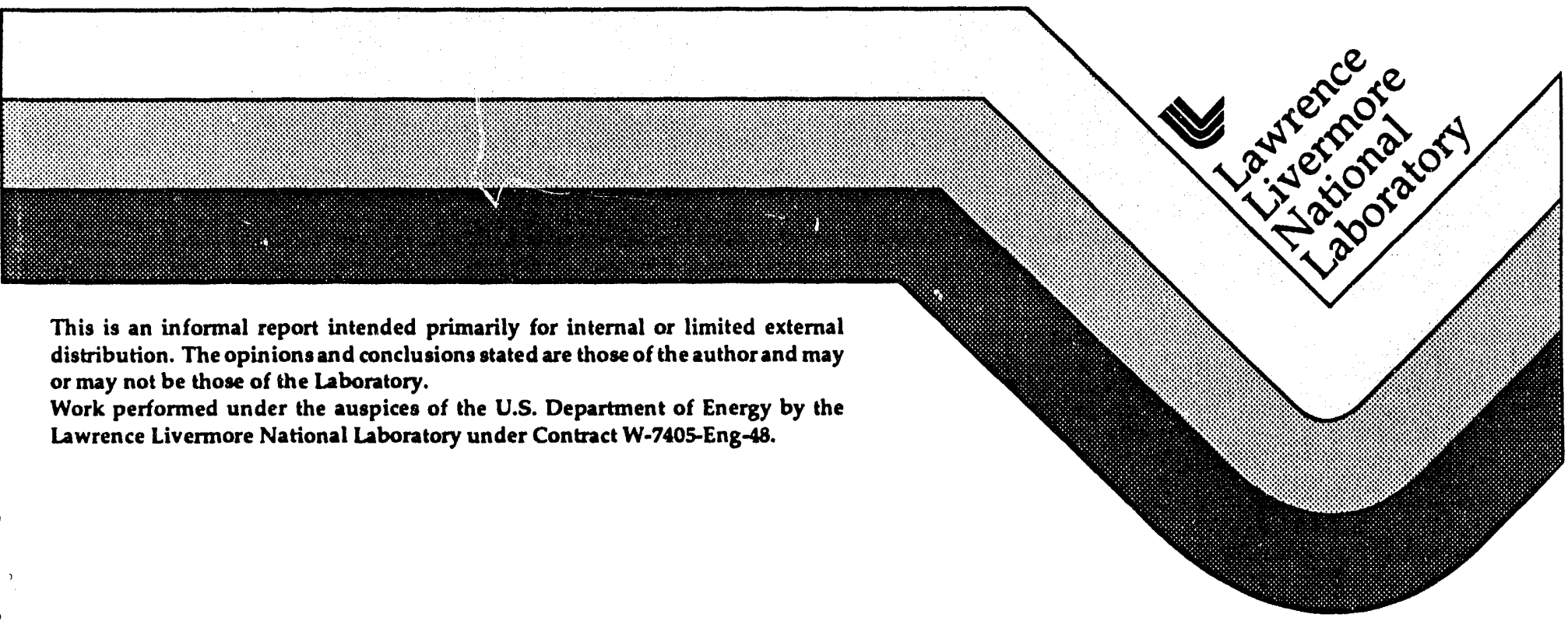




\section{DISCLAIMER}

This document was prepared as an account of work sponsored by an agency of the United States Government. Neither the United States Government nor the University of California nor any of their employees, makes any warranty, express or implied, or assumes any legal liability or responsibility for the accuracy, completeness, or usefulness of any information, apparatus, product, or process disclosed, or represents that its use would not infringe privately owned rights. Reference herein to any specific commercial products, process, or service by trade name, trademark, manufacturer, or otherwise, does not necessarily constitute or imply its endorsement, recommendation, or favoring by the United States Government or the University of California. The views and opinions of authors expressed herein do not necessarily state or reflect those of the United States Government or the University of California, and shall not be used for advertising or product endorsement purposes.

This report has been reproduced directly from the best available copy.

Available to DOE and DOE contractors from the Office of Scientific and Technical Information

P.O. Box 62, Oak Ridge, TN 37831

Prices available from (615) 576-8401, FTS 626-8401

Available to the public from the

National Technical Information Service

US. Department of Commerce

5285 Port Royal Rd.

Springijeld, VA 22161 


\section{Table of Contents}

Preface

LLNL-iv

Safeguards Technology Program

STP-1

Introduction

STP-1

Summary of Major Accomplishments.

STP-1

Task Description and Quarterly Progress..

STP-2

I. NDA MC\&A Measurement Technology R\&D........... STP-2

- Intelligent Actinide Analysis System ........................ STP-2

II. Emission and Transmission Computed

Tomography

STP-3

- Emission and Transmission Computed Tomography Application

STP-4

III. Support to DOE Facilities in Implementation, Testing and Evaluation of LLNL Developed

NDA Techniques.

STP-4

IV. Monte Carlo Calculations of Gamma-

Ray Spectra

STP-5

Appendix A: A Summary of all Milestones and

Deliverables for the Quarter.

STP-7

Appendix B: A List of all Publications Produced During

This Quarter.

STP-8

Safeguards Systems Studies

SSS-1

Introduction

SSS-1

Summary of Major Accomplishments.

SSS-1

Task Description and Quarterly Progress.

SSS-2

I. Safeguards Systems Studies No. LLNL 91019-93.

SSS-2 
II. Analysis of $S \& S$ requirements of Treaties that Impact DOE Mission.

III. VA Fundamentals and ASSESS Courses.

IV. Electronic Transfer of Personnel Security Data Technology Development.

Appendix A: A Summary of all Milestones and Deliverables for the Quarter.

Appendix B: A List of all Publications Produced During This Quarter.

Computer Security - Distributed Systems

Introduction

CSS-1

Summary of Major Accomplishments

CSS-1

Task Description and Quarterly Progress

CSS-4

I. Network Security Monitor (NSM)

CSS-4

II. Distributed Audit Standards

CSS-5

III. Computer Security Guidelines Development.

CSS-6

IV. Security Profile Inspector for Unix

CSS-6

V. Security Profile Inspector for VMS

CSS-6

VI. Computer Incident Advisory Capability (CIAC).........

CSS-7

VII. Computer Security R\&D-CSPM

VIII. Computer Viruses: Prevention, Detection and Mitigation

Appendix A: A Summary of all Milestones and Deliverables for the Quarter.

Appendix B: A List of all Publications Produced During This Quarter. 
DOE Automated Physical Security..............................................PAS-1

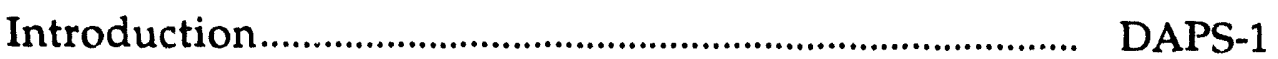

Summary of Major Accomplishments.............................. DAPS-1

Task Description and Quarterly Progress............................. DAPS-2

Appendix A: A Summary of all Milestones and Deliverables for the Quarter.................................................. DAPS-5

Appendix B: A List of all Publications Produced During This Quarter.

DAPS-5

DOE Automated Visitor Access Control System DAVACS-1

Introduction DAVACS-1

Summary of Major Accomplishments DAVACS-1

Task Description and Quarterly Progress..................... . DAVACS-2

Appendix A: A Summary of all Milestones and Deliverables for the Quarter DAVACS-7

Appendix B: A List of all Publications Produced During This Quarter DAVACS-9 


\section{Preface}

The Lawrence Livermore National Laboratory (LLNL) carries out safeguards and security activities for the Department of Energy (DOE), Office of Safeguards and Security (OSS), as well as other organizations, both within and outside the DOE. This document summarizes the activities conducted for the OSS during the fourth quarter of Fiscal Year 1993 (July through September, 1993).

The nature and scope of the activities carried out for OSS at LLNL require a broad base of technical expertise. To assure projects are staffed and executed effectively, projects are conducted by the organization at LLNL best able to supply the needed technical expertise. These projects are developed and managed by senior program managers. Institutional oversight and coordination is provided through the LLNL Deputy Director's office.

At present, the Laboratory is supporting OSS in five areas:

- Safeguards Technology

- Safeguard System Studies

- Computer Security

- DOE Automated Physical Security

- DOE Automated Visitor Access Control System

The remainder of this report describes the activities in each of these five areas. The information provided includes an introduction which briefly describes the activity, summary of major accomplishments, task descriptions with quarterly progress, summaries of milestones and deliverables and publications published this quarter.

The LLNL welcomes the opportunity to apply its expertise in these technical areas. Although the aggregate of activities for OSS is modest, LLNL strives to provide quality responses to OSS needs and stands ready to assist OSS on these and other technical areas.

If OSS management or staff have questions about this report or LLNL's capability to assist in satisfying an OSS need, contact L. Lynn Cleland, 510/4224951 , or one of the program managers for the four technical areas. 


\title{
Safeguards Technolıgy Program
}

\author{
Wayne D. Ruhter, Program Manager \\ Nuclear Chemistry Division
}

\section{INTRODLICTION}

The Safe:suards Technology Program (STP) is a program in LLNL's Nuclear Chemistry Division that develops advanced, nondestructive-analysis (NDA) technology for measurement of special nuclear materials. Our work focuses on $R \& D$ relating to $x$ - and gamma-ray spectrometry techniques and to the development of computer codes for interpreting the spectral data obtained by these techniques.

\section{SUMMARY OF MAIOR ACCOMPLISHMENTS}

\section{NDA MC\&A Measurement Technology R\&D}

Intelligent Actinide Analysis System (IAAS)

- During the last quarter mechanical retrofits to the IAAS have been completed.

- Changes in the electronic configuration and grounding system of the IAAS have been made.

\section{Emission/Transmission Computed Tomography}

- Analysis has been completed of data from an active computed tomography (ACT) scan of a molten-salt-extraction (MSE) button.

- As a result of this analysis, several voids and cracks have been identified in the button which affect the attenuation of Pu and Am gamma-rays, and this may affect the reported relative $\mathrm{Pu}$ and $\mathrm{Am}$ content.

III. Support to DOE Facilities in Implementation, Testing and Evaluation of LLNL Developed NDA Techniques

- A demonstration release of SpecView, a Microsoft Windows-based spectral viewing application was distributed at the INMM Annual Meeting in Scottsdale.

- The hardware for a plutonium isotopic and concentration solution counter was assembled and is being tested. (LLNL funded) 


\section{Monte Carlo Simulation of Gamma-Ray Spectra}

- We used the MGA code to analyze measured and Monte Carlo simulated HPGe gamma-ray spectra for standard Plutonium Isotopic Determination Intercomparison Exercise (PIDIE) sources \#3 and \#7, and the simulated spectrum of source \#2.

- Analysis of a simulation of PIDIE source \#1 with a factor of ten increase in the number of particle tracks indicates that a characteristic pattern in the residual after an MGA fit of the simulated spectrum is due to statistical effects.

\section{TASK DESCRIPTIONS AND QUARTERLY PROGRESS}

Accomplishments achieved during the fourth quarter of FY93 by STP are described below:

\section{NDA MC\&A Measurement Technology R\&D}

$\begin{array}{lcr}\text { B\&R No. } & \text { Funding } & \text { Obligated } \\ \text { GD060102 } & \$ 310 \mathrm{~K} & \$ 310 \mathrm{~K}\end{array}$

The overall objective for this task is to research and develop state-of-the-art nondestructive analysis (NDA) instruments, methods, and techniques that address top priority material control and accountability (MC\&A) problems and will result in improved MC\&A of SNM at DOE facilities. Activities include assistance to the field in resolving major and significant problems associated with holdup, heterogeneous materials, lump corrections, waste measurements, and shipper-receiver measurements.

\section{Intelligent Actinide Analysis System}

\section{Zachary M. Koenig, William M. Buckley, Wayne D. Ruhter, and Austin L. Prindle}

The intelligent actinide analysis system (IAAS) is a gamma-ray spectrometry system utilizing a distributed computer network that is intended to advance nondestructive actinide analysis systems for nuclear safeguards in performance, automation, ease of use, adaptability, systems integration, and extensibility to robotics. A major goal for these systems is a modular hardware and software design that will use commercially available components whenever practical to reduce development and maintenance costs. This will also allow easy modification for specific user requirements or technological extensions to the base instrument design. Another goal is to improve performance by assisting measurement technicians in setup and operation of the system for assurance of spectral data quality and results. The first system will be delivered to Materials Management at LLNL. Materials Management is supporting the hardware, documentation, and training costs. 
Since the IAAS instrument was installed in the LLNL Plutonium facility, problems with electrical ground loops and radio frequency noise have been encountered. These interferences affect the energy resolution of the Ge-detectors. Considerable time has been spent this last quarter trying to understand the source of the noise and to take corrective action to improve the energy resolution of the detectors. Implementation of several software changes to the user interface have been postponed until the electronic problems have been resolved. Retrofits to the mechanical part of the system have been completed. Changes were made to the positioning mechanism that aligns the absorber wheel, as well as installing absorbers with a larger diameter to prevent unwanted gamma-ray scattering. A presentation on the design and initial operating characteristics of the IAAS was given at the INMM annual meeting in Scottsdale Arizona in July. Final preparations for an operator training class for the IAAS are nearing completion.

\section{Emission/Transmission Computed Tomography}

$\begin{array}{lcc}\text { B\&R No. } & \text { Funding } & \text { Obligated } \\ \text { GD060102 } & \$ 150 \mathrm{~K} & \$ 150 \mathrm{~K}\end{array}$

This technology combines the advantages offered by two well-developed, nondestructive assay techniques: gamma-ray spectrometry and computed tomography (CT). Coupled together these two techniques may be used to nondestructively and quantitatively measure uranium and plutonium in samples where the $\mathrm{U}$ and/or $\mathrm{Pu}$ are heterogeneously distributed, distributed in lumps of varying size, or the sample matrix varies in density and composition. This technology potentially offers significant improvements over current segmented gamma-scanning (SGS) techniques.

Gamma-ray spectrometry passively and nondestructively measures the gamma-ray emissions from a sample. From the measured gamma-ray spectrum one can identify the radioactivities detected and determine their abundances, if appropriate corrections for sample self-attenuation are made. Transmission or active CT is a nondestructive technique, already widely used in medical and industrial applications, that uses an external-radiation beam to map photon attenuation within a sample. This attenuation data can be used to correct the emission data for sample self absorption. The result is an accurate, quantitative assay of all detectabie radioactivities within a sample regardless of its form or composition. 


\section{Emission and Transmission Computed Tomography Application Tzu-Fang Wang, and David C. Camp}

We have finished the analysis of the active transmission computed tomography (ACT) scan data collected for the molten-salt-extraction (MSE) button described in the last quarterly report. The results of this analysis show several voids and cracks inside the MSE button which can not be observed by visual inspection or a normal radiograph image. Undetected voids and cracks can change the attenuation of the gamma-rays from either $\mathrm{Pu}$ or Am significantly compared to the attenuation determined from the standard model for homogeneous material. Unfortunately, due to the recall of the MSE button, we are unable to complete the analysis of the pass:ve emission computed tomography (PCT) scan data. These data are necessary to determine the distribution of the $\mathrm{Pu}$ and $\mathrm{Am}$ within the button. We will try to acquire another MSE button in the next fiscal year so that a compete ACT and PCT measurement can be made.

We have begun plans to digitize the three-dimensional ACT image data. With our knowledge of voids and cracks from the ACT scan, and knowing the total weight of the button, we will try to extract some information of the Am and $\mathrm{Pu}$ content of the button without using the PCT scan data.

\section{Support to DOE Facilities in Implementation, Testing and Evaluation of LLNL Developed NDA Techniques}

B\&R No. $\quad$ Funding $\quad$ Obligated

GD060302 \$103K \$103K

The primary objective of this task is to assist DOE sites in implementation of LLNL developed NDA technology; in particular, assist Westinghouse Savannah River Company facilities; LLNL's Materials Management; and LANL's TA-55 facility. A brief description of activities under this task are given below.

We continued to support the LLNL Plutonium Reduction Project. The processing, measurement and data certification phase of The LLNL Inventory Reduction Project was completed on October 29, 1993. Packing and shipment of the remaining samples is in progress. Shipment is dependent on receiver sites opening for the receipt of plutonium. During the inventory reduction approximately 1200 gamma-ray spectrum analyses were performed with the MGA code. This allowed us to test the MGA code under a variety of conditions. In several of the very high ${ }^{241} \mathrm{Am}$ samples we could only measure the ratio of $241 \mathrm{Am}$ to $239 \mathrm{Pu}$. The MGA code will have to be programmed to recognize some of these very difficult spectral conditions and take appropriate action to warn the user and proceed with the analysis in a different manner than in a routine analysis. 
A demonstration release of SpecView, a Microsoft Windows-based spectral viewing application was distributed at the INMM Annual Meeting in Scottsdale Arizona. Work is progressing on a Unix/Motif version of SpecView. This application contains a viewing 'engine' which should form the basis of new data acquisition, manipulation, analysis, and management applications. This will provide a common, vendor-independent graphical user interface that should simplify operations of systems and reduce training requirements. The first analysis application to use the SpecView 'engine' is MGA. The winMGA application was demonstrated at the INMM Annual Meeting in Scottsdale.

System integration and software development is progressing on a Plutonium Solution Assay Instrument for Analytical Chemistry at LLNL. This instrument will provide the first production use of the MGA program for quantitative analysis of plutonium solutions. The hardware for this system has been assembled and is being tested.

We expect to hear from LANL NMT-4 concerning upgrades to the Advanced Isotope Analysis System(AIAS) system and the development of a two-detector robotic instrument for the Los Alamos Plutonium Facility. The AIAS upgrade may provide the first operational use of the SpecView graphical user interface.

\section{Monfe Carlo Calculations of Gamma-Ray Spectra}

$\begin{array}{lcr}\text { B\&R No. } & \text { Funding } & \text { Obligated } \\ \text { GD060102 } & \$ 165 \mathrm{~K} & \$ 165 \mathrm{~K}\end{array}$

Monte Carlo Simulation of Plutonium Gamma-Ray Spectra Joseph B. Carlson, and Tzu-Fang Wang

The simulation of gamma-ray spectra for a known radioactive source, sample matrix, and geometry can be an important tool in designing and understanding non-destructive analysis (NDA) instruments such as $\mathrm{Pu}$ gamma-ray isotopic analysis systems. There are also a number of significant and major MC\&A problems associated with heterogeneous materials, lump corrections, holdup, waste, and shipper-receiver measurements that can be addressed with this calculational tool. The gamma-ray spectra from each of these problems can be simulated with a Monte Carlo method by mocking up various geometries and transporting the gamma-rays of a known source through the material to a detector. Monte Carlo calculations may be used to calculate plutonium "standard" gamma-ray spectra that may be used to determine such characteristics as systematic biases in spectral data-analysis codes. With so many possible variations of the problems described above, the simulation of gamma-ray spectra from them is more efficient and cost effective than the development and measurement of various reference materials. 
Using techniques developed at LLNL we had made Monte Carlo simulations of the HPGe gamma-ray spectra of standard Plutonium Isotopic Determination Intercomparison Exercise (PIDIE) sources \#1 through \#7; gamma-ray spectra of PIDIE sources \#1, and \#3 through \#7 had been measured experimentally. During the last quarter, MGA was used to analyze the simulated spectra for sources \#2 through \#7, and the experimentally measured spectra for the sources \#3 through \#7. The results of MGA analyses of measured and simulated spectra for PIDIE source \#1 were reported at the recent meeting of the Institute for Nuclear Materials Management at Scottsdale.

The simulated and measured spectra are in good agreement as is shown by the MGA fits of peak heights, and by the overall background level as shown from the overlay of the two spectra. However, the residuals after the MGA fit to the Monte Carlo simulated spectra show a characteristic pattern. To test our hypothesis that this pattern is due to a lack of statistical accuracy in the simulated gamma-ray backgrounds, we extended our simulation of PIDIE source \#1 to include ten times more particle tracks. Analysis of this extended simulation with MGA showed significantly reduced residuals compared to the analysis of the previous simulation with one-tenth the data. For the previous simulation, QFIT $=3.06$ and NQFIT $=$ 1.073, while for the simulation with ten times as many particle tracks, QFIT $=1.33$ and NQFIT $=1.011$. The pattern in the residuals after the MGA fit was substantially reduced for the simulation with ten times more particle tracks. Simulations are also being run with ten times as many particle tracks for PIDIE sources \#2 through \#7. A paper summarizing the results of these simulations is being prepared for Nuclear Instruments and Methods.

A continuing issue with operating system problems on the MCNP computer cluster has been worked on in consultation with the vendor. We have received and installed a pre-FCS (first customer shipment) version of their next software release in an attempt to solve the problems. 
APPENDIX A: A SUMMARY OF ALL MILESTONES AND DELIVERABLES FOR THE QUARTER

I. NDA MC\&A Measurement Technology R\&D

B\&R No. $\quad$ GD060102

Mechanical retrofits to the IAAS instrument were completed.

A report on the IAAS effort was given at the INMM meeting

II. Emission/Transmission Computed Tomography

B\&R No. $\quad$ GD060102

Analysis of ACT scan data of an MSE button was completed, revealing several cracks and voids in the button.

III. Support to DOE Facilities in Implementation, Testing and

Evaluation of LLNL Developed NDA Techniques

B\&R No. $\quad \underline{G D 060302}$

A demonstration release of SpecView, a Microsoft Window-based spectral viewing application was distributed at the INMM annual meeting in Scottsdale Arizona.

A report on the SpecView effort was given at the INMM meeting

IV. Monte Carlo Calculations of Gamma-Ray Spectra

B\&R No. $\quad$ GD060102

MGA analysis of Monte Carlo simulated and measured HPGe spectra for standard plutonium sources was performed.

We have simulated a spectrum for one standard plutonium source with ten times as many tracks to investigate the source of patterns in the residuals after the MGA fit of a simulated spectrum.

A report on the Monte-Carlo calculations to date was given at the INMM meeting 
APPENDIX B: A LIST OF ALL PUBLICATIONS PRODUCED DURING THIS QUARTER

The following presentations were made at the annual meeting of the Institute of Nuclear Materials Management in Scottsdale Arizona.

MONTE CARLO SIMULATIONS OF PLUTONIUM GAMMA-RAY SPECTRA, Zachary M. Koenig, Wayne D. Ruhter, Tzu-Fang Wang, Joseph B Carlson, Lawrence Livermore National Laboratory

THE LAWRENCE LIVERMORE NATIONAL LABORATORY INTELLIGENT ACTINIDE ANALYSIS SYSTEM, Wiliam M. Buckley, Joseph B. Carlson, Zachary Koenig, Lawrence Livermore National Laboratory

GAMMA-RAY SPECTRAL ANALYSIS SOFTWARE DESIGNED FOR EXTREME EASE OF USE OR UNATTENDED OPERATION, William M. Buckley, Joseph B. Carlson, William A. Romine, Lawrence Livermore National Laboratory 


\section{Safeguards Systems Studies}

R. Scott Strait, Deputy Associate Program Leader

Fission Energy and Systems Safety Program

\section{INTRODUCTION}

The purpose of the program is to develop systematic approaches and analytic tools for evaluating and enhancing the effectiveness of safeguards and security systems. We develop methodologies and tools for evaluating material control and accountability systems, measures protecting against insider threats, and measures that may contribute to the deterrence of threats. We transfer the technology developed through workshops and field consultations, and we evaluate available tools to determine their applicability to DOE safeguards and security interests. We also provide technical support to OSS on program planning, assessment and integration, and implications of arms control treaties.

\section{SUMMARY OF MAIOR ACCOMPLISHMENTS}

- Completed refinements to ASSESS Protracted theft module and the associated material accounting activity database;

- Submitted ASSESS article to OSS News \& Views newsletter;

- Prepared a paper on radiological and toxicological sabotage evaluation;

- Supported the Central Training Academy in teaching three VA Fundamentals Courses; and

- Confirmed feasibility of using existing electronic commerce approaches, SF-86 software, and live-scan fingerprint systems in the DOE Security Clearance Electronic Processing, Transfer, and Recordkeeping (SCEPTR) System now under development. 


\section{TASK DESCRIPTIONS AND OUARTERLY PROGRESS}

I. Safeguards Systems Studies LLNL 91019-93

$\begin{array}{ccc}\text { B\&R No. } & \text { Funding } & \text { Obligated } \\ \text { GD 06-02-05 } & \$ 230 \mathrm{~K} & \$ 217 \mathrm{~K}\end{array}$

This task develops systematic approaches and analytic tools for evaluating and enhancing the effectiveness of safeguards and security systems. We develop methodologies and tools for evaluating material control and accountability systems, measures protecting against insider threats, and measures that may contribute to deterrence of threats. We also transfer the technology developed through workshops and consultations, as needed. We provide field assistance in the application of evaluation methods, and tools. We evaluate available tools to determine their applicability to DOE safeguards and security interests.

Earlier this fiscal year, we had completed all programming for the ASSESS Insider module, as well as the other ASSESS modules programmed by LLNL-the Manager and Hand-off Collusion modules. During this quarter we distributed ASSESS updates to field users who requested updates (about 12 requests), and at this point, personnel from all the major DOE sites have the updated version of ASSESS. During this quarter, we also submitted ASSESS to the Energy Science and Technology Software Center (ESTSC), in compliance with DOE Order 1360.4B. The ESTSC will not distribute ASSESS without OSS concurrence. The latest version of ASSESS is version 2.2B, released in September. (Although the LLNL modules have not changed since the 2.2A release in May, the Sandia modules have-thus the new version number).

At our May program review, we were asked to provide input for OSS News \& Views rather than publish our own newsletter. This quarter, we provided that input to Ken Render of Battelle PNL, and the articles we submitted are slated for the next issue of News \& Views (originally scheduled for publication October 1). We anticipate receiving many requests for ASSESS after the publication of the newsletter.

This quarter we completed our refinements to the Material Accounting (MA) database in the new Protracted Insider module of ASSESS, developed to support the requirement (in DOE 5633.3A) to perform vulnerability assessments for protracted theft or diversion. We completed all the user input templates for the various MA activities, and we finalized the database mapping logic. One addition to the templates this quarter was the provision for specifying "electronic" for the implementation of MA activities, reflecting the fact that new technologies are automating more and more aspects of 
material accounting. We documented the MA database philosophy and structure in a paper presented to the Institute of Nuclear Materials Management (INMM) Annual Meeting in July.

This quarter we contacted the Protracted module beta testers at the Savannah River Site to elicit feedback on the code and database we had supplied earlier in the year. We were told they had not had an opportunity to use the code. (They had previously used and provided valuable feedback for a version of Protracted without a database during FY92). The stated reason was that they had not needed to do a protracted theft VA in the last several months, but they planned to use the code in the future.

The Protracted theft module is ready for distribution to the field, but has not been distributed due to lack of training resources. We have discussed the training options with OSS and CTA, and the most cost-efficient option seems to be to develop a self-guided tutorial. The tutorial would explain the concepts and modelling approach for protracted theft scenarios, as well as teach the ASSESS Protracted module user interface. The tutorial, along with exercises, would be aimed at experienced ASSESS Insider module users. Per CTA request, in July we submitted a proposal for developing this tutorial, and we were recently told that it was likely to get funded this fiscal year.

This quarter we completed our radiological and toxicological sabotage task. Earlier in the fiscal year we were directed by OSS to focus on both radiological and toxicological sabotage, and to focus our efforts on reviewing the sabotage evaluation process contained in DOE Notice 5630.3A (formerly 5630.3) and related guidance. This quarter we finished the review of the eight-step evaluation procedure contained in the notice, and further explained in separate Defense Programs and Environmental Restoration and Waste Management guidance. As the guidance referred to many other regulations and methods, we also obtained and reviewed the EPA and OSHA regulations and the RPM and CAMP risk methods.

Overall, we found the procedure and guidance to be a sound comprehensive approach for sabotage evaluation, but we also identified some potential pitfalls that may arise in the course of the analysis. In particular we highlighted issues and suggested workarounds for the use of the risk-based screening rules, the use of the RPM and CAMP methods, and the screening of high-consequence, low-probability events. We also suggested an alternative screening and ranking approach using information contained in the HAZMAT databases maintained by DOE sites. We documented this effort in an INMM paper presented at the July Annual Meeting. 


\section{Analysis of Safeguards and Security Requirements of Treaties that Impact DOE Mission}

$\begin{array}{ccc}\text { B\&R No. } & \text { Funding } & \text { Obligated } \\ \text { GD 05-08-03 } & \$ 207 \mathrm{~K} & \$ 73 \mathrm{~K}\end{array}$

This task provides OSS with comprehensive technical reviews of the safeguards and security implications of pending arms control treaties. Under this task, we analyze impact on DOE sensitive facilities and related inspection readiness planning requirements. W/e also evaluate alternative approaches to readiness to determine most efficient methods to achieve treaty compliance and protect DOE vital assets.

This quarter we did not provide OSS with support on treaty requirements, but we were tasked to provide technical support to OSS on risk-related topics. In particular, reviewed an audit of DOE safeguards and security and provided technical comments on: graded probability of occurrence; graded physical protection requirements for Cat I and II facilities; and cost-effectiveness of proposed upgrades. We also provided technical support on options for integrating insider protection elements into the conditional risk equation. For this effort, we reviewed the approach suggested by Defense Programs, we discussed merits of approaches of varying complexity, and we graphed the effects of using various formulas to alter the current conditional risk equation.

\section{VA Fundamentals and ASSESS Courses}

$\begin{array}{ccc}\text { B\&R No. } & \text { Funding } & \text { Obligated } \\ \text { GD 05-06-02 } & \$ 121 \mathrm{~K} & \$ 116 \mathrm{~K}\end{array}$

This task supports the DOE Central Training Academy (CTA) in preparing course materials and presenting safeguards courses in areas of LLNL expertise. This quarter, we supported CTA in the presentation of three Vulnerability Assessment (VA) Fundamentals Courses-one at CTA and the other two at Rocky Flats.

We have been working with CTA to limit our teaching role to the most technical course subjects as CTA personnel take on an expanded teaching role. Our teaching role in VA Fundamentals declined through the year-for the last few courses we taught only the Insider vulnerability assessment methods section. Next fiscal year, CTA plans to also teach the insider VA section without LLNL support. We continue to have a major teaching role in the 
ASSESS Course, and CTA personnel have not yet begun to have substantial participation. However, we have proposed areas of the course for transfer to CTA personnel next fiscal year. CTA has told us that they plan the development of an advanced VA course, and they have requested our participation in that endeavor.

The Protracted theft module is ready for distribution to the field, but has not been distributed due to lack of training resources. We have discussed the training options with OSS and CTA, and the most cost-efficient option seems to be to develop a self-guided tutorial. The tutorial would explain the concepts and modelling approach for protracted theft scenarios, as well as teach the ASSESS Protracted module user interface. The tutorial, along with exercises, would be aimed at experienced ASSESS Insider module users. Per CTA request, in July we submitted a proposal for developing this tutorial, and we were recently told that it was likely to get funded this fiscal year.

In addition to our CTA support of VA training, we also trained Russian representatives in insider threat VA methods and the ET insider VA computer program. (ET wâs developed by LLNL for OSS and was completed in 1987.) This training was conducted jointly with Sandia, who taught outsider threat VA methods and the SAVI outsider VA computer program. The training was in support of DOE's physical protection assistance for the Underground Russian Fissile Material Storage Facility to be built at Tomsk-7. Per OSS request, we performed a security impact assessment for the release of the ET program and forwarded it to Larry Wilcher of OSS. We have also forwarded copies of the trip report detailing the Russian training to OSS personnel. The funding for this training was provided by the U.S. Army Corps of Engineers to Sandia, and Sandia subcontracted to LLNL for ET training.

IV. Electronic Transfer of Personnel Security Data Technology Development

$\begin{array}{ccc}\text { B\&R No. } & \text { Funding } & \text { Otligated } \\ \text { GD-06-02-04 } & \$ 200 \mathrm{~K} & \$ 130 \mathrm{~K}\end{array}$

This is the first task in a three-year project. The overall project will develop an integrated system for the electronic transfer of personnel security data between the DOE and the Office of Personnel Management (OPM) and between DOE Operations Offices. This system for Security Clearance Electronic Processing, Transfer, and Recordkeeping (SCEPTR), will use existing hardware and software to the extent possible. The system will be compatible with the OPM main frame computer in Boyers, PA, and with currently Federal Bureau of Investigation (FBI) approved electronic imaging for transfer of fingerprints. DOE operations to be automated include the clearance process at the field offices and the contractor sites. 
This quarter, we began the systems analysis of the current paperwork process, the identification of all information flows, and the users needs and requirements. An important part of this work was the investigation of the feasibility of using existing technologies. We have examined the feasibility of adapting the following existing software and hardware technologies:

- LLNL Electronic Commerce (EC) approach and software

- SF- software applications

- Electronic fingerprint systems.

Our investigation of the feasibility of using the LLNL EC approach and software indicated that trusted multi-part electronic mail messages are an efficient and secure means for transporting security clearance data between contractor site clearance offices and DOE field offices, and between DOE field offices and OPM. In addition, many of the EC software technologies could provide effective components of the SCEPTR system.

We completed a preliminary analysis of the DOE HQ-funded SF-86 software using PerFORM Pro software. The primary function of the current version of the software is to produce acceptable printed forms. Accordingly, all of the data validation desired by the OPM and all of the personal computer platform compatibility desired by contractor sites were not built into the system. However, our review indicates that it is feasible and cost-effective to adapt and expand the capabilities of the DOE HQ-funded software by using PerFORM Pro Filler under Windows, DOS, and Macintosh. PerFORM Pro is the leading product in this area. It is also practical to extract data from these forms packages into a trusted electronic mail message for transport.

Our review of FBI-approved, commercially provided live-scan fingerprint systems indicates that it is practical to access, extract, store, and forward livescan fingerprint images using a vendor-supplied remote server. We are pursuing the feasibility of a less expensive and more flexible approach to access and extract the fingerprint images using a personal computer gateway concept. The images can be transported using electronic mail, and then submitted to ARIS or sent to a printer. Images are not interchangeable between different companies' products. 


\section{APPENDIX A: SUMMARY OF MILESTONES AND DELIVERABLES:}

I. Safeguards Systems Studies LLNL 91019-93

B\&R No. GD 06-02-05

- The VA New sletter, published jointly with Sandia, was scheduled for February. We requested and received from OSS a delay in this newsletter to accommodate an UCNI review of ASSESS. At our May program review, we were directed to not publish a separate newsletter, but rather provide input to the OSS newsletter. This input was provided during the 4 th quarter.

- The ASSESS Documentation and User's Manual reflecting new software features was completed during the second quarter. It was distributed to attendees of the May ASSESS Course.

- The ASSESS Protracted module, including database, and enhanced rollup capabilities were completed.

- The ASSESS module for evaluating violent insiders using force against barriers was completed in the second quarter.

- Provided report on radiological and toxicological sabotage vulnerability assessments.

II. Analysis of Safeguards and Security Requirements of Treaties that Impact DOE Mission

B\&R No. GD 05-08-03

None this quarter.

III. VA Fundamentals and ASSESS Courses

B\&R No. GD 05-06-02

- VA Fundamentals Course presented at CTA, August 2-6.

- Two VA Fundamentals Courses presented at Rocky Flats, September 14-17 and September 20-23. 
IV. Electronic Transfer of Personnel Security Data Technology Development

B\&R No. GD 06-02-04

- The study of the feasibility of existing hardware and software technologies was completed and a copy of a report "Feasibility of Adapting Existing Software and Hardware Technologies," Sept. 30, 1993, was delivered to OSS. 


\section{APPENDIX B.A LIST OF ALL PUBLICATIONS PRODUCED DURING THIS}

QUARTER

1. "A Database Model for Evaluating Material Accountability Safeguards Effectiveness against Protracted Theft," Alan Sicherman, David S. Fortney, and Cherie Jo Patenaude, July 1993, UCRL-JC-114597.

2. "Issues in Sabotage Vulnerability Assessments," Thomas A. Edmunds and David S. Fortney, July 1993, UCRL-JC-114817.

3. "Feasibility of Adapting Existing Software and Hardware Technologies," September 30, 1993. 


\title{
Computer Security - Distributed Systems
}

\author{
Doug L. Mansur, Program Manager \\ Computer Security Technology Center
}

\section{INTRODUCTION}

The Computer Security Technology Center (CSTC) serves the Department of Energy and its community by providing expertise and solutions to the many information security problems present in today's computer systems and networks. Incidents of intrusions, computer viruses, the purposeful replacement of legitimate software for illegal purposes and similar acts, and vulnerabilities are being addressed by the creation of security software, the delivery of incident response expertise, and research and development into secure systems.

\section{SUMMARY OF MAIOR ACCOMPLISHMENTS}

\section{Network Security Monitor (NSM)}

Work continued on meeting the goal of releasing the first formal version of the NSM monitor this fall. Several algorithms used to make detection more robust in the face of expected network problems were prototyped. Demonstrations and presentations were made to various representatives of the U.S. Navy, the U.S. Air Force, and other U.S. government agencies.

\section{Distributed Audit Standards}

Debra Banning of SPARTA, Inc., presented a paper at the 16th National Computer Security Conference in September on the work to date of the Distributed Audit Standards research she is carrying out under the guidance of LLNL.

\section{Computer Security Guidelines Development}

Requests for copies of the "VMS Security Guideline" continue to be received. A new format has been established for an enhanced version of the document that will encompass VMS versions $5.2-6.0$.

\section{Security Profile Inspector for Unix}

SPI/UV 3.0 is in limited beta release at LLNL while in the ADPR\&I review process. The full release is expected in early Novi:mber. SPI 3.0 employs the revised data-extraction and data-sharing capabilities. SPI 3.0 is undergoing 
beta testing on SunOS, Solaris, DEC/Ultrix, SGI/IRIX, HP/HPUX, and Cray/UNICOS platforms. The security inspection modules and overall package have seen significant enhancements.

\section{Security Profile Inspector for VMS}

All SPI 3.0 security tools have been converted to employ Configuration Query Language (CQL)-supplied system data. The VMS data-extraction libraries are under development and are expected to service the CQL system early in 1994. The recently implemented data-sharing format, together with the new dataextraction architecture, will allow implementation of distributed inspections in late FY94.

\section{Computer Incident Advisory Capability (CIAC)}

The Computer Incident Advisory Capability (CIAC) assisted DOE sites with computer security incident handling and provided research into new security vulnerabilities.

CIAC presented two Incident Handling Workshops during this quarter at DOE facilities.

CIAC was unusually busy with Advisory/Information Bulletins, issuing nine of these which addressed significant problems with Cray/UNICOS, FTP, various SUN utility issues, Novell, the Satan Bug Virus, and an automatic network vulnerability scanning tool. The information resource services, Felicia and Irbis, also continued to be accessed regularly by our DOE constituency.

The Project Management Plan (PMP) was completed and approved. The only modification remaining is to adjust the timelines to 4.5 instead of 5.5 team members. The PMP will be reviewed periodically by CIAC, DOE $/ \mathrm{HQ}$, and DOE/SAN.

\section{Computer Security R\&D-CSPM}

Additional security testing criteria, directed toward the certification and accreditation efforts mandated for Compartmented Mode systems, were reviewed as they became available from the authors at Los Alamos National Laboratory. Further meetings were held at DOE Germantown to discuss the direction and content of the initial draft documents. 


\section{Computer Viruses: Prevention, Detection, and Mitigation}

The computer virus research activities are carried out by the faculty, staff, and graduate students at UC Davis under the guidance of LLNL. The dynamic analysis components of the Malicious Code Testbed (MCT) now automatically recognize two general classes of behavior: execution of decrypted code and capture of DOS system call interfaces. 
TASK DESCRIPTION AND OUARTERLY PROGRESS

I. Network Security Monitor (NSM)

B\&R No. Eunding Obligated

GD060103 \$53K \$53K

Several meetings involving technical exploration, as well as project review, were held both in Livermore and at U.C. Davis.

The following enhancements were made to the network intrusion detection package NSM.

Duplicate, Out-of -order, and Missing Data Problem

The Transcript module was enhanced to handle these exceptions regularly seen in TCP network traffic. The immediate effect is cleaner playback of captured traffic. These techniques will later be folded into the Analysis module where pattern recognition will become more robust due to the handling of these kinds of problems.

\section{Thumb printing}

Setup negotiations that are part of the TELNET and FTP protocols are now recognized and filtered. This will enable 1) more automatic control of terminal window setup when r'aying back sessions, and 2) elimination of extraneous protocol information, thus making the thumbprint signature statistic sharper. A "thumbprint" is a unique signature developed to identify or relate one user session or stream to its simultaneous counterpart elsewhere on the network. A report on this work is in preparation.

\section{Key Fact Capture}

Several Key Fact Capture mechanisms were built and used by U.C. Davis on behalf of a third party U.S. government agency under separate funding. These were ad hoc complex signature recognition schemes that do not yet constitute a network intrusion detection product. A report on this work is in preparation and it is likely that further effort will be devoted to this.

\section{Limited Regular Expression Recognition}

Algorithms for string recognition, where errors are present in the session data, were coded and tested. These may have limited application to the missing data problem mentioned above. How and whether to fold it into NSM is to be decided. 


\section{Utility Command Line Option Enhancements}

An enhancement was made to the report utility where sessions can be sorted by the recognized intrusion signature string. This is especially useful when looking for a repeat of a session by a known cracker.

The analyze utility can now be invoked with a file name to be analyzed. The previous functionality of specifying an epoch with the files being in a known archive directory is still available.

Presentations were made to two more potential DoD NSM clients and to other interested parties from another government agency.

Working beta copies of NSM software were given to interested parties at LLNL and LANL.

We started review and usage of NSM in preparation for a formal release from Livermore, working usability and documentation issues. The released version will be known as NID, the Network Intrusion Detector monitor. Choosing this name will avoid a name conflict with another product, NSM, in the commercial computer security field that bears little resemblance to our work.

We pursued further research of protocols for later NID protocol enhancement. We also consulted with a major vendor's engineering group (Sun) on perceived security needs in system software.

Finally, we researched replacement equipment for continued development and test of NID. Old equipment is being called back by a sponsor of a previous project under whose funds it was purchased. Replacement workstations, PC's, and peripherals will now be retained by LLNL.

\section{Distributed Audit Standards}

$\begin{array}{lll}\text { B\&R No. } & \text { Funding } & \text { Obligated } \\ \text { GD060103 } & \$ 95 \mathrm{~K} & \$ 95 \mathrm{~K}\end{array}$

Work continued on the expansion of the audit Management Information Base (MIB) to determine what is and is not useful information from operating systems. Participation in an OSE implementor's workshop on security and network management also occurred. A paper on "A Prototype Distributed Audit System" was presented at the 16th National Computer Security Conference in September. 
III. Computer Security Guidelines Development

B\&RNo. Eunding Obligated

GD060303 \$31K \$31K

Debra Banning continued responding to requests for the "VMS System Security Guideline." A new format has been established and a complete rewrite of the document is planned. The new document will encompass VMS versions 5.2 - 6.0 and incorporate an increased number of checklist items with expanded text descriptions.

IV. Security Profile Inspector for Unix

B\&R No. Eunding Obligated

$\begin{array}{lll}\text { GD060103 } & \$ 189 \mathrm{~K} & \$ 189 \mathrm{~K}\end{array}$

SPI/UV 3.0 is in limited beta release at LLNL while in the ADPR\&I review process. The full release is expected in early November. This release of SPI employs UNIX data-extraction libraries. The SPI 3.0 series features a revised architecture employing OS-specific data-extraction libraries to isolate system dependent code from the security inspection modules. The goal is a common set of inspection codes for both UNIX and VMS systems, supporting distributed multi-host inspections from a central command client. SPI 3.0 is undergoing beta testing on SunOS, Solaris, DEC/Ultrix, SGI/IRIX, HP/HPUX, and Cray/UNICOS platforms.

The security inspection modules have seen significant enhancements. The System Profile function is now implemented entirely in Configuration Query Language (CQL), a flexible interpreter serving as a front-end to the data extraction libraries, resulting in improved accuracy. System change detection has been consolidated in a single Change Detection Tool (CDT.) This system manages change detection reporting for files and user accounts, and allows aggregation of subsets according to those attributes of files and accounts considered significant for change detection. The Password Security Inspector (PSI) module has been strengthened with additional password tests.

V. Security Profile Inspector for VMS

$\begin{array}{lll}\text { B\&R No. } & \text { Funding } & \text { Obligated } \\ \text { GD060103 } & \$ 189 \mathrm{~K} & \$ 189 \mathrm{~K}\end{array}$

All SPI 3.0 security tools have been converted to employ Configuration Query Language (CQL)-supplied system data. Such data conform to a unified security 
model extending to both VMS and UNIX security elements. This allows SPI to use a common set of security tools for both VMS and UNIX system inspections. The VMS data-extraction libraries are under development and are expected to service the CQL system early in 1994.

In addition, all security tools now report their finding in a common datasharing format. This format is highly orthogonal, so that reports gathered from multiple hosts may be easily combined and treated by the recently developed SPI Report Generator to produce variably organized final reports. This capability, together with the new data-extraction architecture, will allow implementation of distributed inspections in late FY94.

The SPI 3.0 User's Guide has been extensively revised to reflect the new product capabilities and enhancements.

The SPI project leader has consulted with representatives from Sun Soft, Sun Federal, Purdue University, and NIST on the issue of a vendor-supported standard for the generation and sharing of file integrity cryptochecksums.

VI. Computer Incident Advisory Capability (CIAC)

B\&R No. Funding $\quad$ Obligated

$\begin{array}{lll}\text { GD060303 } \$ 490 \mathrm{~K} & \$ 490 \mathrm{~K}\end{array}$

The Computer Incident Advisory Capability (CIAC) team members continued to assist DOE sites with numerous computer security incidents.

In addition, CIAC presented two workshops during this quarter. Richard Feingold presented an "Introduction to CIAC" and "Electronic Resources for Security Related Information" classes at an Oak Ridge AISS training session. Rich, Karyn Pichnarczyk, and Allan Van Lehn did the LLNL workshop. Since LLNL requested an abbreviated form of CIAC's usual presentation, time was spent in modifying the current two-day format. Allan revised the workshop modules "Introduction to CIAC" and "Insiders and Intruders." Karyn presented 3 modules: "Malicious Code and Countermeası :es, Legal Issues, and Macintosh System 7"; Rich coordinated the workshop and presented "Overview of Incident Handling, Threats and Countermeasures, Electronic Resources," as well as the Introduction and Conclusion.

Karyn, Steve Weeber, and Harry Bruestle attended the 5th FIRST Conference in St. Louis. Karyn presented a talk on how CIAC handles virus incidents and she distributed her paper entitled "Case Study: November 17 Virus Incident." Steve participated in a "Birds of a Feather" session on Privacy Enhanced Mail and its use by computer security response teams. Karyn and Harry attended the FIRST General Meeting at the end of the conference to represent CIAC's 
interests with the other response teams.

CIAC issued the following advisories/bulletins during this quarter:

D-18 Solaris 2.x expreserve Patches Available

D-19 Attacks on Anonymous FTP Servers

D-20 Summary of SunOS Security Patches

D-21 Novell NetWare LOGIN.EXE Security Patch

D-22 Satan Bug Virus on MS-DOS Computers

D-23 Cray UltraNet Security Vulnerability (Cray Sites only)

D-24 SCO Home Directory Vulnerability

D-25 Automated Scanning of Network Vulnerability

D-26 Cray Finger Daemon Security Vulnerability (Cray Sites only)

CIAC Felicia Bulletin Board System Activity:

$\begin{array}{lccc} & \text { July } & \text { August } & \text { September } \\ \text { Logons } & 46 & 81 & 57 \\ \text { Persons } & 10 & 12 & 11 \\ \text { Sites } & 10 & 8 & 11\end{array}$

CIAC Irbis FTP Server Activity:

$\begin{array}{lccc} & \text { July } & \text { August } & \text { September } \\ \text { Logons } & 318 & 195 & 244 \\ \text { Persons } & 161 & 54 & 73 \\ \text { Files Transferred } & 791 & 290 & 576\end{array}$

In July, Ms. Sandra Sparks was selected as the CIAC Project Leader. Ms. Sparks brings many years of practical administrative, technical, and project management experience to the position. She has been employed at the

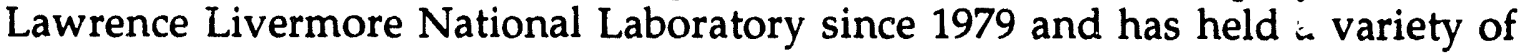
technical and managerial positions, including computer security related assignments. We look forward to her leadership of CIAC to further enhance the services provided to the DOE constituency.

Bill Orvis handled a major computer security incident involving numerous universities and a DOE site. The hacker was identified as a 15 year old from Kansas and the incident was successfully resolved.

Steve Weeber was heavily involved with the handling of an incident at a site in Switzerland. A compromised machine at the site attempted to attack 
computers at a DOE facility. The attack failed, but the network administrator in Switzerland was notified and worked with Steve to trace the source of the attacks.

Karyn Pichnarczyk and Richard Feingold responded to a call from a DOE site in which it was reported that someone had posted the site's password file to a news group. This exposed some of the computers at the site to potential unauthorized access. This incident caused access through ESnet to be denied for 87 hours.

Allan Van Lehn handled an incident involving a DOE site, UC Berkeley, and Sun Microsystems. A student was exploiting the X-Windows system to remotely monitor keystrokes. The student was identified and contacted by university officials. The keystroke monitoring ceased.

Bill Orvis handled a major computer virus incident at another DOE site. He coordinated with the Navy, anti-viral product vendors, and the infected site to get virus scanners in place and to issue information detailing this Satan Bug computer virus problem. This virus is an encrypted, polymorphic type that renders most files useless. Bill issued a CIAC Bulletin as quickly as possible.

Steve Weeber continued to work with individuals at CERN in Switzerland, handling a large incident involving dozens of attackers and sites around the world. Steve added to his set of tools the ability to scan and condense megabytes of log information to compile a list of sites that may have been compromised. He continued to contact individuals at those sites to alert them to the possible intrusion.

Steve also worked with individuals at a DOE site to resolve an incident on an educational machine that was compromised by an attacker coming from the University of Hawaii. The attack was representative of a new trend that CIAC and other response teams have seen: an attacker is able to login and gain root on a machine and leave few or no traces using no known vulnerabilities. CIAC is actively investigating this new trend.

Harry Bruestle responded to two incidents at a DOE site in which intruders attempted to gain access to password files. One of these attacks originated from overseas and passed through a U.S. university before hitting the targeted site. Both incidents involved one-time attacks that were not repeated.

While CIAC Duty Person, Allan Van Lehn responded to a variety of situations, handling incidents involving viruses and Internet attacks. The CERT Coordination Center (CERT/CC) called us about an incident they were working on that pointed to two compromised systems in our constituency. Allan followed up with these sites and alerted them. 
Steve Weeber coordinated the handling of two automated attacks on computers at DOE and other government sites. In the first case, a network intruder had gained access to a machine at a commercial site and was using it to scan remote networks for a vulnerability in the configuration of TFTP. The second case emanated from a compromised account at an educational site. When vulnerable systems were found, the system password file was retrieved and the intruders attempted to decipher the passwords. The compromised accounts at both sites were located and removed. Steve worked with all involved DOE sites to locate and secure vulnerable machines. To our knowledge, no machines at the DOE sites were compromised.

Steve was asked by representatives of a DOE site to participate in an investigation of possible malicious use of one of their systems. Over the course of a week, he worked with the administrators and security personnel responsible for the machine to determine what activities certain users had engaged in. Based in part on the results of that investigation, one employee was terminated.

Karyn Pichnarczyk continued research begun in August on a Novell NetWare problem and issued CIAC Bulletin D-21 Novell NetWare LOGIN.EXE Security Patch. This security problem was first discovered by a DOE contractor, Richard Colby of Chem Nuclear Geotech, Inc. in Grand Junction, Colorado. The distribution of this patch is also unusual-to keep the "world" from accessing irbis.llnl.gov to retrieve this patch-Karyn worked with NIST to make the patch available via anonymous ftp from FIRST.ORG. This is the first time this sort of cooperation with FIRST has occurred with any incident response team.

Bill Orvis continued answering questions concerning the Satan Bug. The FBI has become involved with us and the attacked site in the original Satan Bug incident. They are considering the possibility of investigating this incident since we believe we can identify the name of the virus' author.

It is worth noting that incidents occupied more time than usual for this quarter. The team worked well in sharing valuable expertise and insight to the handling of these incidents supporting the point person. Incidents are becoming more complex and far-reaching and are also occupying the team's attention over greater periods of time, as illustrated by the CERN incident. This trend leaves little extra time for the team to pursue training and awareness, technology watch, and research and development activities. 
VII. Computer Security R\&D-CSPM

B\&R No. Funding Obligated

$\begin{array}{lll}\text { GD060303 } \$ 250 \mathrm{~K} & \$ 250 \mathrm{~K}\end{array}$

Additional security testing criteria, directed toward the certification and accreditation efforts mandated for Compartmented Mode systems, were reviewed as they became available from the authors at Los Alamos National Laboratory. Further neetings were held at DOE Germantown to discuss the direction and content of the initial draft documents.

VIII. Computer Viruses: Prevention, Detection, and Mitigation

B\&R No. Eunding $\quad$ Obligated

$\begin{array}{lll}\text { GD060103 \$53K } & \$ 53 \mathrm{~K}\end{array}$

The dynamic analysis components of the Malicious Code Testbed (MCT) are operational and now automatically recognize two general classes of behavior: execution of decrypted code and capture of DOS system call interfaces. The MCT has been used to perform preliminary dynamic analyses of real-world malicious viruses, such as Jerusalem-B and Tequila.

UC Davis personnel on the malicious code project met again with their counterparts from CIAC to continue information exchange, and to discuss the prospects for potential technology transfer.

In another effort at UC Davis, attempts are being made to pursue static, semiautomatic source code testing to detect possible security flaws in software. The general solution is to generate test data and iterate until sufficient testing is achieved. To date, examples such as trapdoors in a Unix password routine, have been worked out. A number of experimental tools are also being investigated for possible use: GCT, ELI, and ATAC. 
APPENDIX A, A SUMMARY OF ALL MILESTONES AND DELIVERABLES FOR THE OUARTER

I. Network Security Monitor

B\&RNo, GD060103

U.C. Davis submitted annual research progress review to LLNL.

II. Distributed Audit Standards

B\&RNo._GD060103

No milestones or deliverables to report this quarter.

III. Computer Security Guidelines Development

B\&RNo. GD060303

No milestones or deliverables to report this quarter.

IV. Security Profile Inspector for Unix (SPI/UNIX)

B\&R No. GD060303

Delivered SPI/UV 3.0 beta release for testing at LLNL. Full release is expected in early November, pending completion of ADPR\&I review.

V. Security Profile Inspector for VMS (SPI/VMS)

B\&R No. GD060303

Began alpha testing of the VMS data-extraction library for system file information.

VI. Computer Incident Advisory Capability (CIAC)

B\&R No. GD060303

Continued, round-the-clock computer security incident handling service to the DOE community. Created several new warning notices and bulletins, as well as a conference paper.

Project Status Reports 
FAX Vulnerability Study:

By removing the carbon paper roll from CIAC's fax machine, Bill Orvis discovered the roll is readable and has all the faxes printed for the past several months on it. He also continued to investigate ways to break into fax machines and looked for additional vulnerabilities. For example, he borrowed a high-end FAX and is attempting to use the new FAX modems (see below) to try to attack it.

Bill installed new CIAC FAX modems for the group and the group used them a few days later to send out a CIAC notice. We had 4 of the 8 modems set up and sent 175 copies of a 5 page FAX in about 3 hours. The previous method of using a standard fax machine would have taken 12 hours. These new modems are attached to CIAC's Macintosh computers and enable us to send electronic documents directly from the Macintosh to predetermined FAX locations.

Console Password Feature for DEC Workstations document:

Sandy Sparks decided to establish an easier-to-read and use format for CIAC's publications. This was applied to Allan's draft document of VMS console vulnerabilities and he was able to more easily identify areas for improvement. These changes have been made.

Discretionary Control of Local Area Networks:

At the request of John Stush, CIAC drafted a proposal to identify network vulnerabilities. This information in its final form could be used in drafting a network security guideline. Rich and Sandy submitted a draft and CIAC is in the process of satisfying the initial deliverable of a profile of the Novell networking system.

Improving CIAC workshops:

Richard Feingold also pursued his goal of adding a multi-media dimension to the current workshops by visiting LLNL's multi-media Skunkworks. This site provides multi-media resources for Laboratory personnel to use to learn this new technology.

VII. Computer Security R\&D-CSPM

B\&R No. GD060303

No milestones or deliverables to report this quarter.

VIII. Computer Viruses: Prevention, Detection and Mitigation

B\&R No. GD060103

U.C. Davis submitted annual research progress review to LLNL. 

QUARTER

Banning, Debra L., SPARTA, Incorporated, "A Prototype Distributed Audit System," 16th National Computer Security Conference, September 20-23, 1993.

Pichnarczyk, Karyn, "Case Study: November 17 Virus Incident," 5th FIRST Conference, August 10-13, 1993. 


\title{
DOE Automated Physical Security
}

\author{
Greg Davis, Program Manager
}

\section{INTRODUCTION}

The continuing goal of the DOE Automated Physical Security task (DAPS) is to enhance the LLNL developed Argus Integrated Security system to meet DOE security needs and to transfer Argus to the private sector.

The objective is to identify interested companies, generate and provide technical information describing the Argus system, and enter negotiations with the intention of transferring the Argus technology. The transfer may take the form of CRADAs and/or licenses. The licenses may be exclusive for a limited period of time or in a limited market sector.

\section{SUMMARY OF MALOR ACCOMPLISHMENTS}

I. A Joint Work Statement document (JWS) was submitted to the LLNL Technology Transfer department for review and submittal to the DOE for approval. The JWS describes the planned working arrangements between LLNL and Martin Marietta Technology and Information Company (MMTI).

II. The LLNL biometric test was completed, questionnaires distributed and analyzed, and a final report written. The results indicate that the biometric implementation was successful. Biometric personal verification is now operational and supported in the Argus system.

III. The Argus compliance matrix was completed and reviewed. The results indicate that Argus complies with all reviewed Federal orders. Over 246 requirements out of 8 Federal orders were evaluated.

IV. A design concept paper for $\mathrm{N}$-Person rule in a CAIN booth was completed. It outlined implementation rules requiring that a predetermined number of authorized people be present in an area. This was presented at the 4th Quarter OSS Program Review October 14, 1993. 


\section{TASK DESCRIPTIONS AND OUARTERLY PROGRESS}

Accomplishments achieved during the Second quarter of FY93 by STP are described below:

I.

$\begin{array}{lll}\text { B\&\&R No. } & \text { Funding } & \text { Obligated } \\ \text { GD 06 0201 } & \$ 325 \mathrm{~K} & \$ 325 \mathrm{~K}\end{array}$

\section{Argus Enhancement $\quad \mathbf{N}$-person rule}

A presentation at the OSS Program review by Cherie-Jo Patenaude described how N-person rule would be implemented in a CAIN booth. The basic concept is to set up an entry and exit window of time when the system would allow less than the required people to be in an area. The window would be user configurable so that the details of operations in specific areas would be accommodated. The assumption is that the required people would remain in sight through the glass door as they travel one-by-one through the CAIN booth. The system identifies a special start up and shut down phase of operation where these windows are in affect. We believe that this approach is superior to one requiring a booth for each person simultaneously entering an $\mathrm{N}$-person rule area.

\section{Biometric field test}

The biometric field test was completed and a report written. The field test successfully demonstrated the integration of Biometrics into the Argus system on the LLNL production security system at Livermore. It also raised some questions regarding the false-reject rate of the Recognition System Inc. Hand Geometry Unit. The false reject numbers that we obtained vary greatly from those published in the Sandia report cited in the introduction.

We believe that the false-reject problems are connected to the enrollment process and that we dic not update our copy of the biometric template over the period of the test. These should be areas of further investigation.

One surprise is that even with the occasionally high false reject rate when using the HGU, the surveys show that Users believe that the HGU was easy to use and operated well with the Argus Security System.

We believe that the demonstration validated the system for use in areas with limited access lists. However, more testing is needed prior to installation in a high throughput area. We believe that changes in the enrollment process and training, would substantially improve the observed false reject rates. 


\section{Technology Transfer}

A draft Joint Work Statement has been completed and is being reviewed by the LLNL Technology Transfer department and the FESSP Program Office.

A detailed Argus costing model was developed by MMTI after a visit by MMTI staff to LLNL.

Multiple briefings were given to MMTI and BTEC staff to help the marketing and engineering staff understand Argus.

A draft Argus overview document was prepared to assist MMTI in understanding and presenting the salient features of Argus.

We believe that MMTI has actually begun to staff up for the anticipated CRADA. They are anxious to begin work. The issue of securing adequate funds is currently holding back the completion of the rork definition. As written, the CRADA would require approximately $\$ 1 \mathrm{M}$ of DOE funds per year for 3 years. This would be matched by approximately $\$ 2 \mathrm{M}$ of MMTI expenditures per year for the same period.

We believe that it is critical to the successful transfer of the Argus technology that sufficient funds be identified to continue the Technology Transfer. Due to the lack of available DOE CRADA funds, we are beginning to rewrite the Joint Statement of Work to scale back the transfer to fit the available $\$ 250 \mathrm{~K}$ funds from OSS.

\section{Argus Standardization effort}

A Security System Standardization Working Group meeting was hosted at LLNL with one of the main topics being discussions of Argus as a DOE standard security system. Debby Fitzgerald lead the meeting and generated minutes. Tours of the Argus system and technical presentations were given by the Argus staff.

\section{Argus Compliance Matrix}

This quarter we completed the Argus Compliance Matrix study and issued the study as an LLNL report. The purpose of this study was to document the Argus system's compliance with applicable DOE Orders and other federal policy guidance and to identify areas, if any, where Argus is not in compliance. The focus was on the Argus system "as a product," not as installed at LLNL or elsewhere. The compliance matrix lists the text of the requirements cited in the order, indicates whether Argus meets that requirement, and gives needed explanatory information. 
Based on input from the OSS project monitor, we included the following DOE Orders and other regulations:

- DOE 5632.2A, "Physical Protection of Special Nuclear Material and Vital Equipment;"

- DOE M 5632.2B Draft, "Manual for Physical Protection of DOE S\&S Interests;"

- DOE 5632.5, "Physical Protection of Classified Matter;"

- DOE 5632.6, "Physical Protection of DOE Property and Unclassified Facilities;"

- DOE 5632.9A, "Issuance and Control of Security Badges, Credentials, and Shields;"

- DOE 6430.1A, "General Design Criteria;"

- DIAM 50-3, "Physical Security Standards for Construction of Sensitive Compartmented Information Facilities (SCIFs);" and

- W-A-450C, "Federal Specification for Components for Interior Alarm Systems."

The study concluded that Argus complies with the orders and requirements reviewed. However in a few instances, mostly pertaining to SCIFs, Argus compliance can only be achieved with special configuration. For example, DIAM 50-3 contains a requirement that the true identify of a person entering a SCIF not be known to a security guard at the Console. Since Argus displays names to the Console operator, this requirement can only be met if the system contains an alias instead of the true name-an approach suggested in the text of the requirement. Whenever such a special site-specific configuration is required, or other compliance explanation is warranted, explanatory comments are included in the report. 
APPENDIX A, A SUMMARY OF ALL MILESTONES AND DELIVERABLES FOR THE OUARTER

\section{DELIVERABLE STATUS TABLE}

Original

Deliverable Description of Deliverable

12/31/92 Provide DOE with a list of candidate vendors who we believe are interested in accepting the ARGUS technology.

02/28/93 Demonstrate the operation of the 3-D hand geometry device at Building T1677 at LLNL.

03/30/93 Provide to DOE technology transfer documentation and information.

09/30/93 (Changed Deliverable) Report on N person rule

09/30/93 Provide a report summarizing the technology transfer effort, the application of technologies and potential upgrades investigated, and recommendations on future enhancements to this system.

9/30 (New Deliverable) Complete Working group at LLNL on Argus Standardization and provide all necessary information.

$9 / 30$

$9 / 30$
(New Deliverable) Provide the Matrix document. Final Report on Biometrics test due
Status

Delivered

$1 / 12 / 93$

Delivered

$4 / 23 / 93$

Complete

Complete

10/14/93

Completed

$10 / 14 / 93$

Complete

Complete

Complete

\section{APPENDIX B, A LIST OF ALL PUBLICATIONS PRODUCED DURING THIS QUARTER}

UCRL- 12345

UCRL- 56789

DOE Integrated Security System Biometric Field Test Report Argus Integrated Alarm, Access Control, and Assessment System Order Compliance Study 


\title{
DOE Automated Visitor Access Control System
}

\author{
Greg Davis, Program Manager
}

\section{INTRODUCTION}

The continuing goal of the DOE Automated Visitor Access Control System (DAVACS) is to minimize delays experienced by DOE employees and contractors for legitimate classified visits to DOE sites. The systems and procedures developed will be able to support DOE employees and their contractors. The information included in this report covers the 4 th quarter activities.

The current visit authorization procedure (using DOE form 5631.20, formerly the $277 \mathrm{form}$ ) is time-consuming and prone to human error. Lack of proper paperwork or need-to-know authorization create most of the delays to visitors entering DOE sites.

It is desirable to have one straight-forward procedure to process classified visits within the DOE complex. In the framework of current DOE policy and procedures, we will support the implementation of this for DOE visits at the classification level of SRD/NWD or lower. Given timely policy changes, the new visit procedures will support visits involving program need-co-know authorization such as Sigms, AIS, SIS, etc.

\section{SUMMARY OF MAIOR ACCOMPLISHMENTS for 4th Ouarter}

I. The DAVACS Workshop held on July 13, 1993 included a presentation by Eric Steele of the DOE Automated Visitor Access Control System and how it will be implemented at other DOE sites. 150 guests attended this workshop and received DAVACS implementation training as well as documents.

II. Presentations were given by Doug Sweeney, Eric Steele and Scott Strait during the DAVACS workshop held on July 13, 1993.

III. As of $9 / 24 / 93$, eleven DOE facilities are officially using the DAVACS procedures to process incoming visits. These facilities include, Los Alamos National Laboratory, Sandia/NM, Pantex, Oakridge National Laboratory, Y-12, K-25, Argonne National Laboratory, Brookhaven National Laboratory, DOE Chicago and DOE Savannah River.

IV. The biometrics verification task was completed on $8 / 17 / 93$. A biometrics template was successfully acquired from the DISS Query screen and then used 
as part of the biometerics verification procedure. The verification test document was completed on $8 / 25 / 93$.

V. After technical discussions with CYLINK Corporation, manufacturer of the encryption equipment, demonstration of a encrypted dial-up communications link with the DOE/HQ computer system was demonstrated on $9 / 20 / 93$. With the assistance of Leon Grant and Bill Williams of DOE/HQ computer center, encrypted CVCS queries into DISS were accomplished. Document on the encryption test results was completed on $9 / 22 / 93$. A second manufacturer, IRE, of encryption equipment was contacted to demonstrate their device.

VI. Document of a technical approach to improve DISS communications security was completed on $9 / 27 / 93$.

\section{TASK DESCRIPTIONS AND OUARTERLY PROGRESS}

Accomplishments achieved during the 1st, 2nd, 3rd and 4th quarters of FY93 by STP are described below:

I.

$\frac{\text { B\&R No. }}{\text { GD 06 02 }} \quad \frac{\text { Funding }}{575 \mathrm{~K}} \quad \frac{\text { Obligated }}{575 \mathrm{~K}}$

Incorporate the use of DOE information available through $\mathrm{CPCI}$

The first task in the streamlining of the classified visit process was to incorporate the use of the DOE clearance information available through CPCI. In a meeting held at DOE/HQ on Jan. 11, 1993 it was agreed that, instead of using the CPCI access, a new screen would be developed under CVCS for the purpose of verifying the DOE clearance of a visitor. The DOE Integrated Security System (DISS) now has an active screen titled "CVCS Active Clearance Query" and is accessed through CVCS. The screen includes full name, social security number, location of Personnel Security File, Employer, Highest Clearance Level, and the date granted for that clearance. The screen is currently being used by DOE facilities to validate active clearances and approved classified visits. Evaluation will continue for the identification of needed modification as well as the future development of Biometrics. 


\section{Complete the analysis of the DTMS system and a write critique}

As discussed with Carl Pocratsky and Darryl Toms we deleted the Clearance Transmittal Network Project Task and replaced it with the DP-23 Computer System Analysis task. It was determined through discussions with Dan Montgomery at PNL that there is virtually no information available to Livermore on the PNL DTMS system or their follow-up ABCs system. An analysis on either system is not possible at this time. The Computer systems analysis for DP-23 will begin 04/12/93 and be completed 09/15/93.

\section{DP-23 Computer System Analysis Task}

The purpose of doing a systems analysis for DP- 23 was to provide information for improving the speed that Defense Program need-to-know access can be provided for a classified visit. The second purpose of this analysis was to provide DP with information needed to replace the existing WADACS computer system. This computer system has reached the end of its useful life and is becoming more and more difficult to support. The system analysis was completed. This document was delivered to DOE Headquarters along with suggested improvements and a model of the recommended system.

Document new recommended visit procedures, and a plan for implementing them at LLNL.

DOE Order 5631.4A was reviewed and generalized visit procedures were developed and documented for the DAVACS test process. The Standard Operating Procedures (SOP) as well as the LLNL Test Plan was delivered to Ron Sentell and Darryl Toms of the DP-121 office for their review and comments on $03 / 08 / 93$. The SOP includes documentation on the specific responsibilities of the Host, Visitor and Visitor Control office for processing classified visits under the DAVACS test program. This document breaks down the process into a step by step procedure with all responsibilities clearly defined. The DAVACS Test Plan is an in depth look at how the entire DAVACS process works. This document identifies DAVACS background and the delays in the current system as well as the components involved in the project. The test plan focuses on the complex wide use of DISS and specifically the revision of the classified visitor access control procedures to incorporate its use. Its objective is to review and test newly developed procedures for processing classified visits and validate their practical application. The scope defines LLNL responsibilities during the demonstration project and the length of the testing period as well as defining the visit parameters. Test procedures include a description of the test as well as identifying specific items that will be evaluated. 


\section{Implementation of DAVACS test at LLNL.}

The DAVACS test date agreed upon on 03/08/93 with Ron Sentell DP-121 was $04 / 15 / 93$. The official DOE announcement was delayed resulting in the DAVACS test period beginning 05/03/93. Headquarters was unable to participate during the test period. Sandia/Albuquerque began testing 06/07/93 and participated in the evaluation process. Testing of DAVACS was held from $5 / 3$ to $7 / 21 / 93$ with 1430 visits recorded of which 504 were DOE visits and 382 of the visits were done using DAVACS.

Complete implementation package so that the new visit procedure can be implemented at all DOE sites as resources become available.

All aspects of the implementation package have been finalized. These documents included communication requirements, formalized SOP, training requirements, equipment requirements and the policy change announcement. This document was distributed DOE complex wide at the 1993 Access Control Workshop.

Workshop at LLNL to explain the new system to other sites.

The date for the Visitor Control Workshop was moved forward from $07 / 28 / 93$ to $07 / 13 / 93$. Participants were identified for the workshop that included visitor control representatives from all DOE facilities. The agenda was developed to include 1 day on DAVACS related issues as well as 2.5 days on other classified visit procedures. 150 guests attended this workshop and received DAVACS implementation training as well as documents. The DAVACS Workshop held on July 13, 1993 included a presentation by Eric Steele of the DOE Automated Visitor Access Control System and how it will be implemented at other DOE sites. Doug Sweeney gave a presentation on Visitor Biometrics and DISS Encryption. Scott Strait gave a presentation on the automating of the personnel security clearance process to improve its efficiency and effectiveness. 


\section{Complete delivery of the appropriate documentation and training to support}

new procedures on other DOE sites.

The official document for the DAVACS process and guidelines for its implementation in the DOE complex was distributed at the Workshop. The document is UCRL-MI-113646. A question and answer session was held to address individual complications associated with the implementation of DAVACS procedures. We are currently supporting all facilities requesting assistance in their implementation process. These efforts have included aid in drafting personnel notifications and resolving inaccurate data within DISS.

\section{DISS Communication Security Analysis}

The visit to DOE/HQ provided contacts to discuss issues in securing the phone communication lines of the DISS system. Selection and purchase of the encrypting hardware was completed. Preliminary information and design was sent to Joe Juras in preparation of hardware installation at DOE/HQ. The DISS communication security analysis report is currently in progress.

\section{Biometrics Verification}

Routines to control the Recognition Systems Inc. biometrics device were completed. Rob Carpenter, of DOE/HQ computer facility, insured the biometrics template data was inserted into the correct DISS record. Using a Macintosh type user interface, routines to capture the biometrics template and run the biometrics verification were shown. The feasibility of biometrics verification were demonstrated. Biometrics Verification test document was developed.

\section{DISS Communication Security Analysis}

Our original contact, Bob Kight at DOE/HQ, was no longer available. Leon Grant a contractor at the DOE/HQ computer facility was assisting in the test. At the end of August Leon Grant was replaced by Bill Williams.

After installation of the CYLINK encryption device at DOE/HQ initial test encrypting the DISS dial-up communications failed. Several attempt to resolve the problem with CYLINK resulted in a technical representative, Barry Fields, being sent to DOE/HQ to debug the problem. With the help of Bill Williams a solution was found. Software changes and PROM updates were delivered and installed into the encrypting devices. Test of a DISS encrypted link were successful. Documentation of the test and the issues surrounding the failure were generated. 
Due to these problems with the CYLINK encryption device a demonstration of another device was initiated. Information Resource Engineering (IRE) will be sending encrypting devices for testing an encrypted DISS dial-up communications.

\section{DISS Communication Security Analysis}

Issues documented focused on the dial-up communications access to the DISS database. Discussions with Roger Parish from the DOE/HQ computer facility, regarding the DISS system, assisted with the completion of this report.

Contact with IBM Federal Services provided additional information. The documenting of a technical approach to improve the DISS communications security was completed. 
APPENDIX A, A SUMMARY OF ALL MILESTONES AND DELIVERABLES FOR THE OUARTER

I. B\&R No. GD 0620

AUTOMATED VISITOR ACCESS CONTROL TASK FY93 MILESTONES:

02/01/93 CLEARANCE TRANSMITTAL NETWORK PROJECT - Deleted Complete the analysis of the DTMS system and a write critique - Task Deleted. Replaced by DP-23 Computer System Analysis Project. See below.

03/08/93 CLASSIFIED VISIT PROCEDURES IMPROVEMENT PROJECT - Completed Document new recommended visit procedures, and a plan for implementing them at LLNL

05/03/93 CLASSIFIED VISIT PROCEDURES IMPROVEMENT PROJECT - Completed Usage of DISS in LLNL Visitor Control Office. (In-coming visits and all out-going visits to $\mathrm{DOE} / \mathrm{HQ}$ processed by new method. deleted.)

07/01/93 DISS COMMUNICATIONS SECURITY ANALYSIS PROJECT - Completed Complete testing of the technical approach according to the system requirements, and demonstrate the results.

05/15/93 CLASSIFIED VISIT PROCEDURES IMPROVEMENT PROJECT - Completed Standard Operating Procedure and test plan available for DOE/HQ, SNL and other sites.

06/17/93 DISS COMMUNICATIONS SECURITY ANALYSIS PROJECT - Completed Hardware installation of encryption equipment at DOE/HQ DISS and LLNL Visitor Control Office.

07/13/93 CLASSIFIED VISIT PROCEDURES IMPROVEMENT PROJECT - Completed Complete implementation package so that the new visit procedures can be implemented at all DOE sites as resources become available.

07/13/93 CLASSIFIED VISIT PROCEDURES IMPROVEMENT PROJECT - Completed Workshop at LLNL to explain the new system to other sites.

08/13/93 VISITOR BIOMETRICS VERIFICATION PROJECT - Completed Implement the design approach and complete testing according to the system requirements.

09/30/93 DISS COMMUNICATIONS SECURITY ANALYSIS PROJECT - Completed (Document new system requirements and a technical approach to address them. Deleted) Document existing DISS communications protection facilities and the results of the communications line encryption test.

09/30/93 DP-23 Computer System Analysis Project - Completed

Delivery of report on DP-23 Systems Analysis of current computer system (WADACS).

10/01/93 CLASSIFIED VISIT PROCEDURES IMPROVEMENT PROJECT - Completed Complete delivery of the appropriate documentation and training to support new procedures on other DOE sites. 


\section{FY93 DELIVERABLES:}

01/01/93 CLEARANCE TRANSMITTAL NETWORK PROJECT - Final report on the analysis of the DTMS system.

02/01/93 CLASSIFIED VISIT PROCEDURES IMPROVEMENT PROJECT Final report on the identification and definition of required policy and procedure changes.

02/01/93 VISITOR BIOMETRIC VERIFICATION PROJECT - Visitor biometrics requirements document.

02/01/93 CLASSIFIED VISIT PROCEDURES IMPROVEMENT PROJECT Report on the LLNL implementation plan

03/01/93 VISITOR BIOMETRIC VERIFICATION PROJECT - Visitor Biometrics Design Document

04/01/93 DISS COMMUNICATIONS SECURITY ANALYSIS PROJECT Communications security requirements document.

04/01/93 DISS COMMUNICATIONS SECURITY ANALYSIS PROJECT Final report on the DISS communications security analysis.

05/01/93 CLASSIFIED VISIT PROCEDURES IMPROVEMENT PROJECT - Completed Preliminary training and site preparation materials.

06/01/93 CLASSIFIED VISIT PROCEDURES IMPROVEMENT PROJECT Report on the LLNL visit procedures.

09/01/93 VISITOR BIOMETRICS VERIFICATION PROJECT - Completed Final report on the demonstration of the visitor biometrics demonstration. 10/01/93 CLASSIFIED VISIT PROCEDURE IMPROVEMENT PROJECT - Completed Final training and site preparation materials. 
APPENDIX B, A LIST OF ALL PUBLICATIONS PRODUCED DURING THIS QUARTEB

UCRL-CR-114244 Design for the DOE Integrated Security System (DISS) Visitor Biometrics Verification

UCRL-CR-114245 Requirements for the DOE Integrated Security System (DISS) Visitor Biometrics Verification

UCRL-MI-113646 DAVACS Implementation Guide

UCRL-CR-115407 Systems Analysis Of Visitor Sigma Access Approval Process

UCRL-CR-115408 Results of the DOE Integrated Security System (DISS) Visitor Biometrics Verification Test

UCRL-CR-115409 Results from the DOE Integrated Security System (DISS)

Encryption Communication Test

UCRL-CR-114243 DOE Integrated Security System (DISS) Preliminary Communications Security Analysis 

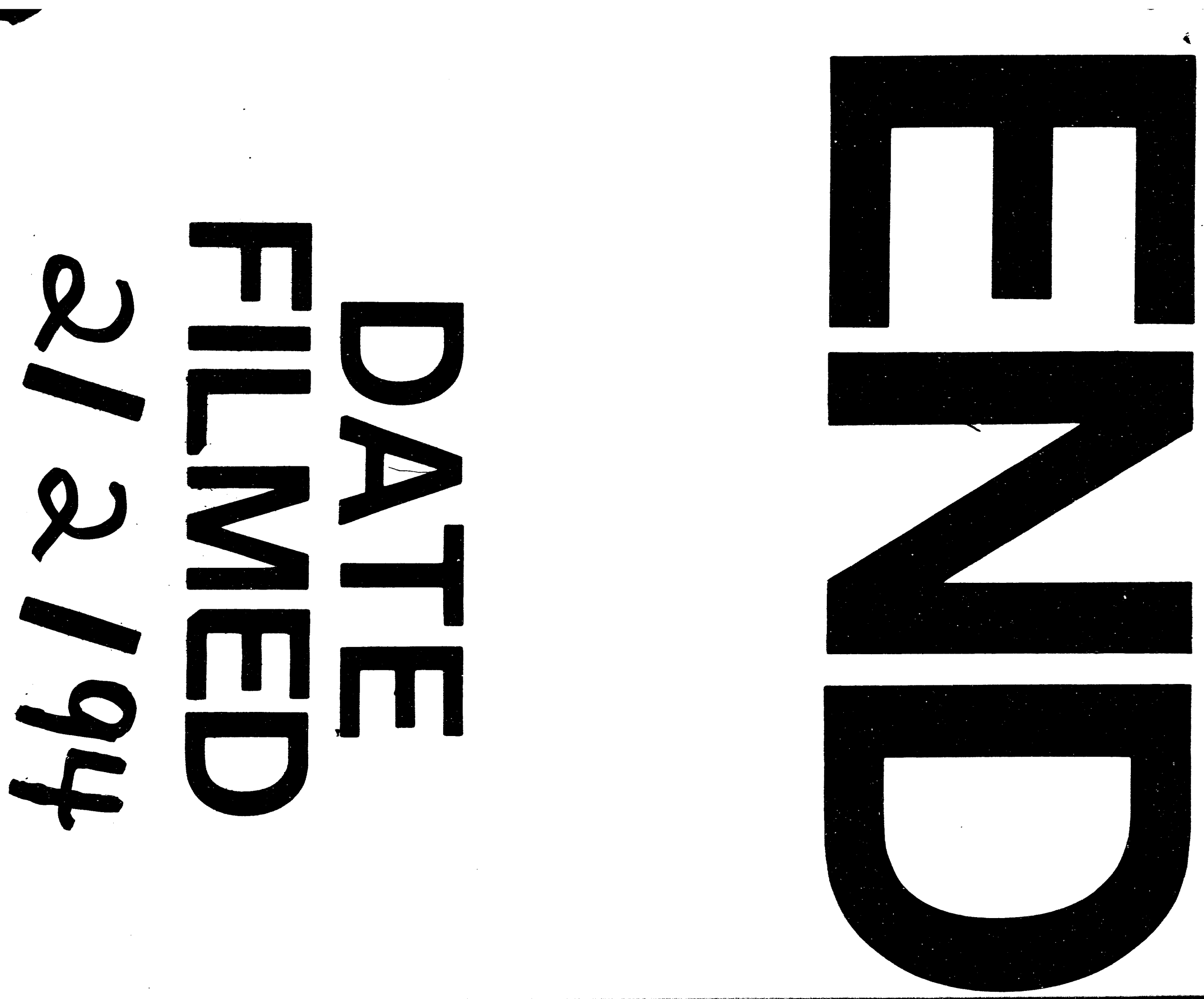

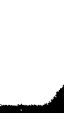


